\title{
Parental education, television exposure, and children's early cognitive, language and behavioral development
}

\begin{abstract}
The association between television exposure and children's development is subject to controversial debates. Heavy television exposure may be detrimental to children by overstimulating their developing brains. It may also infringe on time that children would otherwise spend on more developmentally beneficial activities or parental interactions. In the present analysis, we use data from the 2004/5 birth cohort of the Growing Up in Scotland study to investigate relations between hours of weekly television measured around the ages two to four and as average over this time span with children's linguistic, cognitive, and behavioral outcomes around age five. Our analysis shows differences in the level and growth of television exposure by parental education. However, we did not find any substantive associations between television exposure and children's cognitive or language ability. We found small associations of television exposure with conduct problems and prosocial behavior, particularly for children of less educated parents. Overall, the results suggest that the impact of television on children's development is less pronounced than often assumed.
\end{abstract}

Keywords: Social stratification, Television, Child development, Scotland 


\section{Introduction}

There is ample evidence of differences in leisure activities by socio-economic characteristics, with activities such as reading books or theater visits more prevalent among higher social strata and activities like television and attending sporting events more so among lower social strata (Altintas 2012; Bihagen and Katz-Gerro 2000; Gracia 2015; Notten and Kraaykamp 2009b). Children from different social backgrounds, therefore, are exposed to different patterns of cultural consumption, which have been linked to differences in life course outcomes such as educational attainment (Aschaffenburg and Maas 1997; Bourdieu and Passeron 1990; DiMaggio 1982; Dumais 2002; De Graaf, De Graaf, and Kraaykamp 2000; Kraaykamp and Eijck 2010; Lareau 2003; Notten and Kraaykamp 2009a, 2010). Social differences in childrearing activities may thus play an important role in the intergenerational transmission of social inequality.

However, the consequences of different activities for the development of children's abilities and behavior are still subject to heated debates, particularly in the case of television (Donnellan and Ferguson 2014; Ferguson and Donnellan 2014; Zimmerman 2014). Although there is a large number of empirical studies on the association between children's television viewing and language, cognitive and behavioral development (for a recent review, see Kostyrka-Allchorne, Cooper and Simpson 2017), evidence for a causal relationship between TV exposure and developmental outcomes remains ambiguous. Many studies rely on small samples (e.g. Barr et al. 2010; Chonchaiya and Pruksananonda 2008; Nathanson et al. 2014; Wright et al. 2001) or focus on specific regions (e.g., Linebarger \& Walker, 2005; Schmidt et al., 2009; Zimmerman et al., 2007) or subgroups (Tomopoulos et al. 2010), weakening the precision and generalisability of these results.

Whereas a considerable number of studies on TV consumption and child outcomes is based on longitudinal data, the majority of studies collected information on TV consumption 
at one or two time points and did not consider the cumulative impact of TV consumption on children's development over time. Exposure to television, however, is likely to vary over children's early years and the strength of its relationship with children's development may depend on the sustainment of the exposure over more extended periods (Kostyrka-Allchorne, Cooper and Simpson 2017). Many of these longitudinal studies do not rely on large-scale population-based surveys and deal with rather small sample sizes (for notable exceptions of population-based longitudinal studies see, for instance, Zimmerman and Christakis 2005; Pagani et al. 2010).

In our study, we investigated differences by parental education in TV exposure between the ages of two and four and their associations with children's language ability, inductive reasoning ability, and behavioral development around the age of five. We contribute to the existing literature on TV consumption and child development in several ways. First, we use a comparatively large, nationally representative sample of Scottish children, which allowed us to gauge differences by parental education in the level and trajectory of television exposure across early childhood along with its time-specific (three measurements of TV consumption around age 2, 3, and 4) and cumulative effects on children's developmental outcomes. Other than most previous studies, we investigated a broad range of child outcomes (inductive reasoning ability, expressive language ability, behavior problems), thereby acknowledging that TV consumption may have a different impact on children depending on the outcome considered.

Second, in addition to confounders commonly included in the literature (e.g. socioeconomic status), we were able to account for a rich set of time-constant and, most importantly, time-varying covariates that may influence both television exposure and developmental outcomes. These measures include family structure, mother-child relationship, mothers' views on the importance of educational activities and concern about their child's development, and 
mother and child health. When measuring television exposure cumulatively, accounting for time-varying confounders (in addition to time-constant confounders) is problematic as, for instance, mothers' concern about children's development or health may impact their children's later television exposure but may also change in response to their previous television viewing. To appropriately adjust for time-varying confounders, we used a regression-with-residuals (RWR) approach (Wodtke and Almirall 2017). For expressive language ability and inductive reasoning ability, we were also able to assess whether changes between the ages of 3 and five were related to TV exposure.

Third, we examined whether parental education moderated the developmental consequences of television exposure as a strategy to assess whether families from higher social strata can compensate for any adverse effects of television viewing. There is some evidence suggesting that individual and family factors may moderate the associations between TV consumption and child outcomes (Kostyrka-Allchorne, Cooper and Simpson 2017). Lastly, our analysis corrected for selective loss to follow-up which is a potential source of bias in longitudinal studies of the association between TV consumption and developmental outcomes if children's amount of TV consumption affects the likelihood of remaining in the study.

\subsection{Television exposure by parental education}

Children with highly educated parents may achieve better schooling and labor market outcomes than their peers with lower educated parents via accumulating 'embodied' cultural capital (e.g. linguistic skills, accent) during their upbringing (Bourdieu and Passeron 1990; De Graaf, De Graaf and Kraaykamp 2000; Lareau 2003). Because children acquire 'embodied' cultural capital in daily practices, it is vital to investigate empirically whether children from different socio-economic backgrounds engage in leisure activities differently.

For American families, Lareau's (2003) ethnographic study found that parents from the upper social strata engage their children in cultural activities and organize family time in a way 
that enhances their children's skills and cultural capital - parenting that Lareau calls “concerted cultivation". By contrast, due to financial and time constraints and a less intervening parenting style, children in lower-class households spend more of their time in unstructured activities (including television). Parenting practices of "concerted cultivation" appear to have a positive impact on child development and educational achievement (Bodovski and Farkas 2008; Cheadle 2008; Greeman et al. 2011) and seem to account partially for class differences in academic achievement (Cheadle 2009; Potter and Roksa 2013)

Several quantitative studies confirm Lareau's qualitative study by identifying a negative association between parental socio-economic status and parental time with children spent watching television (Altintas 2012; Bihagen \& Katz-Gerro 2000; Gracia 2015). In general, children with lower educated parents appear to watch more TV than children with highly educated parents (for a systematic review see Cillero and Jago 2010; see also Certain and Kahn 2002; Anand and Crosnick 2005; Christakis et al. 2004; Espinosa et al. 2010). None of these studies, however, considered whether social disparities in television exposure increase, decrease or remain stable across early childhood.

\subsection{Television exposure and children's developmental outcomes}

Watching television may influence young children directly through exposure to the formal features of that medium. Flashing light, rapid scene changes, quick edits and auditory cuts could be overstimulating to developing brains (Christakis 2009; Christakis et al. 2018). Therefore, it may train infants and toddlers to expect immediate and intense environmental input, shorten the concentration span, and make life in reality less exciting (Singer and Singer 1983). Substantial exposure to television may thus induce attentional or other behavioral problems in early childhood or adolescence (Christakis 2009). Experimental evidence shows that fast pacing of TV programs has immediate negative impact on children's behavior (Geist and Gibson 2000; Cooper et al. 2009) and executive function (Lillard and Peterson 2011; 
Lillard et al. 2015). Effective executive function is, in turn, associated with higher academic achievement in math and reading (Cragg \& Gilmore 2014; Christopher et al. 2012).

The direct effect of television exposure may also operate via the so-called "video deficit" (Anderson and Pempek 2005: 511), that is, very young children (younger than 30 month) can imitate live demonstrations easily but struggle at imitating video demonstrations (Barr and Hayne 1999; Hayne, Herbert, and Simcock 2003). Only repeated exposure to televised presentations appears to increase children's ability to imitate what they have seen on television (Barr et al. 2010; Barr, Muentener, and Garcia 2007). In one experiment, a group of two-year-old children successfully retrieved a toy, which someone hid while the children watched through a window. However, when they watched the same event on television, they performed very poorly in the object retrieval task (Schmitt and Anderson 2002; Suddendorf 2003; Troseth and DeLoache 1998). Also, children who interact with a native speaker have better language acquisition than those who learn a language from a screen. This effect was retained even when the native speaker was recorded on tape (Grieser and Kuhl 1988; HirshPasek et al. 1987; Krcmar, Grela, and Lin 2007; Kuhl, Tsao, and Liu 2003; Nelson et al. 1989).

Aside from this direct impact, television exposure may indirectly affect children's development by reducing parent-child interactions and spending less time in activities that are beneficial for children's cognitive ability, language growth and behavioral development. Both regarding language acquisition and inductive reasoning ability parent-child interactions and a stimulating learning environment are deemed conducive in the early ages of a child (Shonkoff and Phillips 2000). Children's vocabulary growth is particularly prone to the immediate environment with more and better linguistic input by parents and caretakers resulting in more advanced vocabulary (Hurtado, Marchman, and Fernald 2008; Huttenlocher 1998; Weisleder and Fernald 2013; Zimmerman et al. 2009). Children's self-regulation of emotion, attention and 
behavior are interrelated and heavily reliant on their relationship with and support by caregivers (Shonkoff and Phillips 2000).

In several experimental studies, a negative link between children's television exposure and the quantity and quality of parent-child interactions was evident (Christakis et al. 2009; Mendelsohn et al. 2008; Tanimura, Okuma, and Kyoshima 2007). Parent-child interactions were fewer not only when children actively watched television but also in the presence of background television. Background television has content not designed for children, which they pay little active attention to, and is left on in the toddler's presence (Kirkorian et al. 2009; Pempek, Kirkorian, and Anderson 2014). Parental co-viewing and more frequent and higher quality interactions can mitigate the harmful effects of television exposure on language development (Fender et al. 2010; Mendelsohn et al. 2010). At the same time, parental coviewing increases attention and responsiveness to media exposure (Barr et al. 2010; Fidler, Zack, and Barr 2010).

Aside from parent-child interactions, self-directed play is as essential for children's development. For instance, results from a randomized controlled trial have shown that block play improves language development among low- and middle-income toddlers (Christakis, Zimmerman, and Garrison 2007). Television exposure in children's households also interferes with children's play. Background television, for instance, significantly reduced the length of toy play and children's attention towards play (Schmidt et al. 2008; Setliff and Courage 2011). It further reduced parental engagement with their children's play (Courage et al. 2010; Kirkorian et al. 2009). Armstrong and Greenberg (1990) also found that background television limits children's cognitive processing capacity when exercising difficult and complex tasks. Other studies found that heavy television exposure has a detrimental impact on children's time spent reading or being read to and on their reading comprehension (Koolstra and van der Voort 1996; Koolstra and Voort 1997; Rideout, Hamel, and Kaiser 2006; Vandewater et al. 2005). 
Despite these findings on the relationships between television exposure, parent-child interactions and child activities, the literature on the associations between television exposure and preschooler's language and cognitive outcomes provides mixed evidence. Many studies found negative associations between exposure to television during early childhood and language, cognitive or math skills (Byeon and Hong 2015; Lin et al. 2015; Laidley and Conley 2018; Pagani et al. 2010; Espinosa et al. 2010; Chonchaiya and Pruksananonda 2008; Huang and Lee 2010; Richert et al. 2010; Tomopoulos et al. 2010; Zimmerman and Christakis 2005; Zimmerman, Christakis, and Meltzoff 2007). Other studies could not provide evidence for this relationship. (Blankson et al. 2015; Gentzkow and Shapiro 2008; Robb, Richert, and Wartella 2009; Schmidt et al. 2009). Nathanson et al. (2014) found a negative relationship between heavy television viewing and young children's executive function. Regarding behavioral difficulties including attention problems, the evidence is similarly mixed: some found positive associations with television viewing (Tomopoulos et al. 2010; Cheng et al. 2010; Christakis et al. 2004; Miller et al. 2006; Mistry et al. 2007; Parkes et al. 2013) but others did not (ConnersBurrow, Mckelvey and Fussell 2011; Foster and Watkins 2010; Stevens and Muslow 2006; Jackson, 2018).

Existing studies mostly rely on a few snapshot measures of TV consumption at specific ages and do not address the cumulative impact children's long-term TV viewing patterns may have on developmental outcomes. The effect of heavy TV consumption via direct or indirect pathways on developmental outcomes may only unfold after longer duration of exposure. In our empirical analysis, we assessed the association between average TV consumption across the ages of 2 to 4 and developmental outcomes around age 5 and adjusted for a rich set of timeconstant and time-varying confounders by using a regression-with-residuals (RWR) approach (Wodtke and Almirall 2017). 


\subsection{Effect moderation by social background}

The context in which TV exposure occurs is considered to be important in the study of TV exposure and child outcomes. Individual factors such as family background may moderate the associations between TV exposure and children's development but potential moderators are rarely considered in the literature (Kostyrka-Allchorne, Cooper and Simpson 2017). Children from lower socio-economic backgrounds may not only watch more television than children from higher socio-economic backgrounds, but television exposure may also have a more detrimental effect on their developmental outcomes. In recent years, studies have demonstrated that the impact of various adverse childhood conditions is less harmful to children from an advantaged socio-economic background (Bernardi 2014; Grätz 2014; Torche and Echevarría 2011). The ability of parents of higher social backgrounds to compensate for potential disadvantages with other resources and activities may underlie this effect moderation. Similarly, we argue that parents from higher socio-economic backgrounds may compensate for children's television exposure with other more cognitively stimulating resources (e.g. expensive toys) and activities (e.g. reading to children, museum visits). Moreover, they might anticipate the potentially adverse effects of television exposure and increase the quality of time spent on other activities with their children, for instance, by talking a lot to their children or by carefully considering the choice of play activities.

Parents from higher socio-economic backgrounds may also choose TV programs that are more suitable for children and their learning than parents from lower socio-economic strata. The content of the TV program matters for children's outcomes. Whereas adult television had adverse relationships with infant cognitive ability or language development (Okuma and Tanimura 2009), child-informative programs were either positively (Barr et al. 2010; Wright et al. 2001), or at least not negatively (Tomopoulos et al. 2010; Zimmermann \& Christakis 2007), associated with these outcomes. Watching educational television was also associated 
with a higher executive function among children from high-risk families (Linebarger et al. 2014). Lillard et al. (2015) found that watching television including fantastical events lowered children's executive function compared to other TV experiences.

Due to this compensatory mechanism among children from higher socio-economic backgrounds, we expect television exposure to be more detrimental to children from lower socio-economic backgrounds whose parents lack resources for compensation. Empirically, several studies have shown that negative associations between TV exposure and language development are more pronounced for children from lower socio-economic backgrounds (Duch et al. 2013; Tomopoulos et al. 2010; Ribner et al. 2017).

\subsection{Research questions}

Against this background, we address three specific research questions:

1) Is children's TV consumption between the ages of 2 to 4 stratified by parental education? Does stratification of TV consumption change throughout early childhood?

2) Does TV consumption around age 2, 3 or 4 have an impact on language growth, cognitive ability and behavior problems around age 5? Is there a cumulative impact of children's TV consumption across early childhood on these outcomes?

3) Is TV consumption between the ages of 2 to 4 more detrimental to children from lower educated households than to children from higher educated households.

\section{Method}

\subsection{Data and Sample}

For our empirical analysis, we used Birth Cohort 1 from the Growing Up in Scotland (GUS) study (ScotCen Social Research 2013), which includes children born between June 2004 and May 2005 and living in Scotland at the time of sampling. Data collection first took place in 
April 2005 through May 2006 when children were around ten months old and were conducted at yearly intervals until children were six years old and biennially afterwards (Anderson et al. 2007). In our study, we used information from the first five waves of data collection (at 10 months and around the ages two, three, four, and five).

The original sample consisted of all babies with eligible birth dates from 130 randomly selected geographic areas. The survey obtained the date of birth and place of residence from Child Benefit records, which held $97 \%$ of Scottish residents with children at this time. Altogether, GUS successfully recruited 5,217 children ( $80 \%$ of 6,583 initially contacted). Our analytical sample excluded minority populations with insufficient case numbers and thus consisted of singleton births by White, opposite-sex or single parents, and for which mothers were the survey respondents at the first interview. Starting at Wave 2, in which consistent reporting of children's television exposure began, we followed the remaining 3,736 children

until the fifth wave of data collection or until the child was lost to follow-up. We classified cases as lost to follow-up as soon as they temporarily or permanently dropped out of the survey, changed to a primary respondent other than the mother, or were observed with missing values on either of the covariates or television exposure. Therefore, we based our analyses on the association between television exposure and developmental outcomes measured around age five on 2,678 children.

\subsection{Measures}

\subsubsection{Child outcomes}

Around their third and fifth birthday, GUS assessed children by a Naming Vocabulary and a Picture Similarities task, both part of the British Ability Scales, Second Edition (Elliott, Smith, \& McCulloch, 1996; Elliott, Smith, \& McCulloch, 1997). Naming Vocabulary measures expressive language ability and knowledge of nouns by asking children to identify different 
objects in a colored picture booklet. The Picture Similarities assessment captures children's inductive reasoning ability by asking them to match a picture card (e.g. an animal) to one of four other picture cards (e.g. a house, a person, a car or another animal) based on whether they see any conceptual or elementary link. We used measures provided by GUS, which correct for differences in item difficulty.

In wave 5, GUS provides parents' responses to Goodman's (1997) Strengths and Difficulties Questionnaire $(S D Q)$, a validated and widely used instrument for measuring children's socio-emotional and behavioral development between the ages of four to sixteen. Respondents rate 25 statements about their children as 'Certainly true', 'Somewhat true', or 'Not true'. The statements are combined into five scales, each built on five items, capturing the following constructs: hyperactivity/inattention $(M=3.53, S D=2.24)$, emotional symptoms $(M$ $=1.15, S D=1.37)$, conduct problems $(M=1.66, S D=1.40)$, peer relationship problems $(M=$ $0.92, S D=1.28)$, and prosocial behavior $(M=8.26, S D=1.61)$. To detect relations between television exposure and particular aspects of behavioral and socio-emotional difficulties, we followed previous studies (e.g. Parkes et al. 2013; Cheng et al. 2013) and considered the five scales as separate outcomes in our analysis.

\subsubsection{Television exposure}

We measured children's amount of television exposure as the total number of hours children watch television during an average week around the ages of two, three, and four. The mother of the child provided this information. We generated this measure from information on hours of television exposure during an average weekday, an average weekend, and the number of days on which the child watched television during the week. For each year, we topcoded this information at the value of the 99.5 -percentile. To capture the cumulative impact of 
television exposure on cognitive and behavioral outcomes, we considered the average hours of children's television exposure across ages two to four.

\subsubsection{Time-constant confounders}

Based on theoretical considerations, we selected covariates that may affect the amount of children's television exposure at a given time while at the same time influencing children's cognitive and behavioral outcomes at a later point (see Table S1 and Tables S2 in the Appendix for summary statistics on all variables). Some of these covariates were time-invariant, either because they cannot change over time or were measured only in the first or second wave. We included indicators of the child's sex, mother's age at birth ('younger than 20', '20 to 29', '30 to 39', '40 or older', available as categorical variable only), highest educational degree of the parents at first interview ('no qualification', 'lower secondary education', 'upper secondary education', 'vocational and postsecondary education certificates or diplomas', 'higher education'), mothers' views on the importance of educational activities (e.g., reading, writing, painting) around age 2 ('very important' coded 1; 'quite important', 'neither important nor unimportant', 'not really important', 'not at all important' coded 0), and mother-child relationship at age 10 months. The latter was measured using four items from Condon and Corkindale's (1998) Maternal Postnatal Attachment Scale. The items cover the mother's feelings of annoyance/irritation, (in)competence, (im)patience and resentment with her child, with ranked responses ranging from 'Almost all the time' to 'Never'. After splitting the answer categories into positive and negative ones, we counted the positive answers across items. A score of 4 was coded as '1', indicating good mother-infant attachment, while a score below 4 was regarded as a problematic attachment and coded as '0' (cf. Chanfreau et al. 2011). 


\subsubsection{Time-variant confounders}

In addition to these time-constant covariates, a child's television exposure in a given year likely depends on characteristics that change over time. We were able to account for the following time-varying variables that have all been measured around age two, three and four: maternal employment status, family structure, maternal health, household income, the type of region families live in, and neighborhood deprivation status. We also included a measure of children's health and mothers' concern about children's development that may affect children's television exposure but may at the same time be affected by earlier television exposure. GUS collected mothers' self-reported employment status at each interview as full-time employed, part-time employed, or not working. We measured family structure by the number of siblings living in the household ('none', 'one', 'two or more') and by whether the mother has no partner, is married, or cohabiting. Maternal health is based on whether the mother reported that she was not in good health ('fair' and 'poor' vs 'excellent', 'very good', and 'good'). To account for economic resources and opportunities we controlled for household income, the type of region (less than 10,000 residents; 10,000 to 124,999 residents; 125,000 residents and more), and whether the current residential area was located in the lowest quintile of the Scottish Index of Multiple Deprivation (SIMD), a composite measure of local area poverty. Mothers also reported on their child's health ('very good', 'good', 'fair', 'bad', 'very bad') and they expressed the level of concern about their child's development ('no concerns', 'some concerns', 'a lot of concerns') in a given year.

\subsection{Analytical Strategy}

Our analysis proceeded in three steps. First, we described differences by parental education in television exposure between the ages two to four. The respective model includes an interaction 
between parental education and the linear time trend. Children's sex is the only control variable in this analysis.

Second, we estimated the associations between children's developmental outcomes and television exposure around the ages of two to four separately. TV consumption may be more or less linked to developmental outcomes depending on the timing of exposure. The literature review suggests that TV consumption has a stronger impact on under three year olds than on older children (Kostyrka-Allchorne, Cooper and Simpson 2017). To address the cumulative effect of television exposure on children's outcomes around age five, we also considered the average television exposure across this period. To interpret the estimated associations as causal effects of television exposure, we explored alternative explanations for these associations, mainly confounding (i.e., an association between television exposure and developmental outcomes through common causes) and attrition bias (Elwert and Winship 2014; Winship and Mare 1992).

We dealt with confounding by controlling for the measured covariates outlined above while assuming that there are no (important) unmeasured confounders. In our age-specific models, we accounted for all time-constant confounders and the time-varying confounders in each age respectively. In our model including a measure of average television exposure, we included all time-constant and time-varying confounders.

The inclusion of time-constant factors in the cumulative model is straightforward, but controlling for time-varying covariates can be methodologically challenging (Robins and Hernán 2009). Time-varying confounders (in our case, child health and concern about the child's development) may be affected by prior television exposure and thus mediate some of the effects of television exposure on developmental outcomes (see Figure S1 in the Appendix). Controlling for these covariates would then lead to over-control bias (i.e., underestimating the cumulative effect of television exposure). Also, the effect of television exposure on our 
outcomes may be biased if accounting for time-varying confounders opens up non-causal pathways via unmeasured common causes of time-varying confounders and developmental outcomes (i.e., collider bias). Therefore, we used a two-stage regression-with-residuals (RWR) approach (Wodtke and Almirall 2017) which adjusts for time-varying confounders without inducing over-control bias and collider bias. In the first stage, we regressed time-varying covariates child health, $\mathrm{H}_{\mathrm{t}}$, and concern about the child's development, $\mathrm{C}_{\mathrm{t}}$, around ages three and four on past television exposure, $\mathrm{X}_{\mathrm{t}-1}$, time-constant covariates, $\mathrm{Z}_{0}$, and past time-varying covariates, $\mathrm{Z}_{\mathrm{t}-1}$. From these models we obtained the residuals, $H_{t}^{*}$ and $C_{t}^{*}$ for both variables:

$$
\begin{aligned}
& H_{t}^{*}=H_{t}-E\left(H_{t} \mid X_{t-1}, Z_{0}, Z_{t-1}\right) \\
& C_{t}^{*}=C_{t}-E\left(C_{t} \mid X_{t-1}, Z_{0}, Z_{t-1}\right) .
\end{aligned}
$$

We obtained residuals for both variables around age two by centering around the unconditional mean. In the second stage, we estimated the following linear regression models,

$$
Y_{5}=\beta_{0}+\beta_{1} \bar{X}_{t}+\beta_{2} \mathbf{Z}_{0}+\beta_{3} Z_{t}+\beta_{4} H_{t}^{*}+\beta_{5} C_{t}^{*}+\varepsilon_{y}
$$

where the respective (standardized) developmental score around age five, $Y_{5}$, is a function of our cumulative measure of average television exposure through ages two to four, $\bar{X}_{t}$, a vector of time-constant covariates, $Z_{0}$, a vector of time-varying covariates $Z_{t}$, and the residualized time-varying confounders $H_{t}^{*}$ and $C_{t}^{*}$. Because these residuals are independent of prior television exposure, their adjustment does not induce over-control bias (and collider bias) while at the same time eliminating confounding by these variables (for an illustration see Figure S2 in the Appendix), assuming that we correctly specified the confounder models (i.e. the models from which we obtained the residuals). To account for the additional uncertainty from estimating residuals, we obtained all model parameters and their standard errors through bootstrapping. 
To address potential effect heterogeneity by parental background, we re-estimated the models for average television exposure separately for children whose parents obtained an education below upper secondary and those whose children did obtain upper secondary or more.

To deal with the issue of attrition bias, we corrected for nonrandom loss to follow-up by estimating stabilized inverse probability of attrition weights (Robins, Hernan, \& Brumback, 2000),

$$
\operatorname{saw}_{i}=\prod_{t=3}^{5} \frac{\left.P\left(A_{\mathrm{it}}=0\right] A_{\mathrm{i}(t-1)}=0, X_{\mathrm{i}(t-1)}, z_{\mathrm{i0}}\right)}{P\left(A_{\mathrm{it}}=0 \mid A_{\mathrm{i}(t-1)}=0, X_{\mathrm{i}(t-1)}, z_{\mathrm{io}}, Z_{\mathrm{i}(t-1)}\right)},
$$

that is, the ratio of the probability that the individual is not lost to follow-up at time $t$ conditional on prior television exposure and time-constant covariates and the same probability conditional also on time-variant covariates at time $t-1$ multiplied over ages three to five. We used logistic regression models to calculate these probabilities (see Table S3 in the Appendix). Using these weights in the analyses described above creates a pseudo-population in which loss to followup is independent of measured covariates. Generally, lower parental education, single motherhood, and living in a deprived area were among the significant predictors of attrition.

\section{Results}

\subsection{Early television exposure by parental education}

First, we test the hypothesis whether early television exposure is socially stratified. Figure 1 shows the predicted weekly hours of television across ages two to four for different parental education groups (see Model 5 in Table S4 in the appendix). Around age two, there was already a gap of almost 1.5 hours in weekly television exposure between children whose parents had a degree and children whose parents had either no qualification or a lower secondary qualification. Children whose parents attained upper secondary education or vocational/postsecondary certificates took an intermediate position. Subsequently, average 
weekly television exposure increased across all five groups. However, this increase was more pronounced for children whose parents had less education. In other words, the gap in weekly television exposure between children whose parents have different levels of education widened as they aged. Around age four, children whose parents had a degree watched almost 10 hours of television during a week, on average, compared to 14 hours for children whose parents had no qualification and around 12 hours for the other three groups. Overall, these results support the claim that children's television exposure is socially stratified and more common among families in the lower social stratum.

Figure 1. Predicted weekly hours of television exposure, by age and parental education, obtained from growth curve model with random intercepts and random linear age trend (see Model 5 in Table S4 in the Appendix)

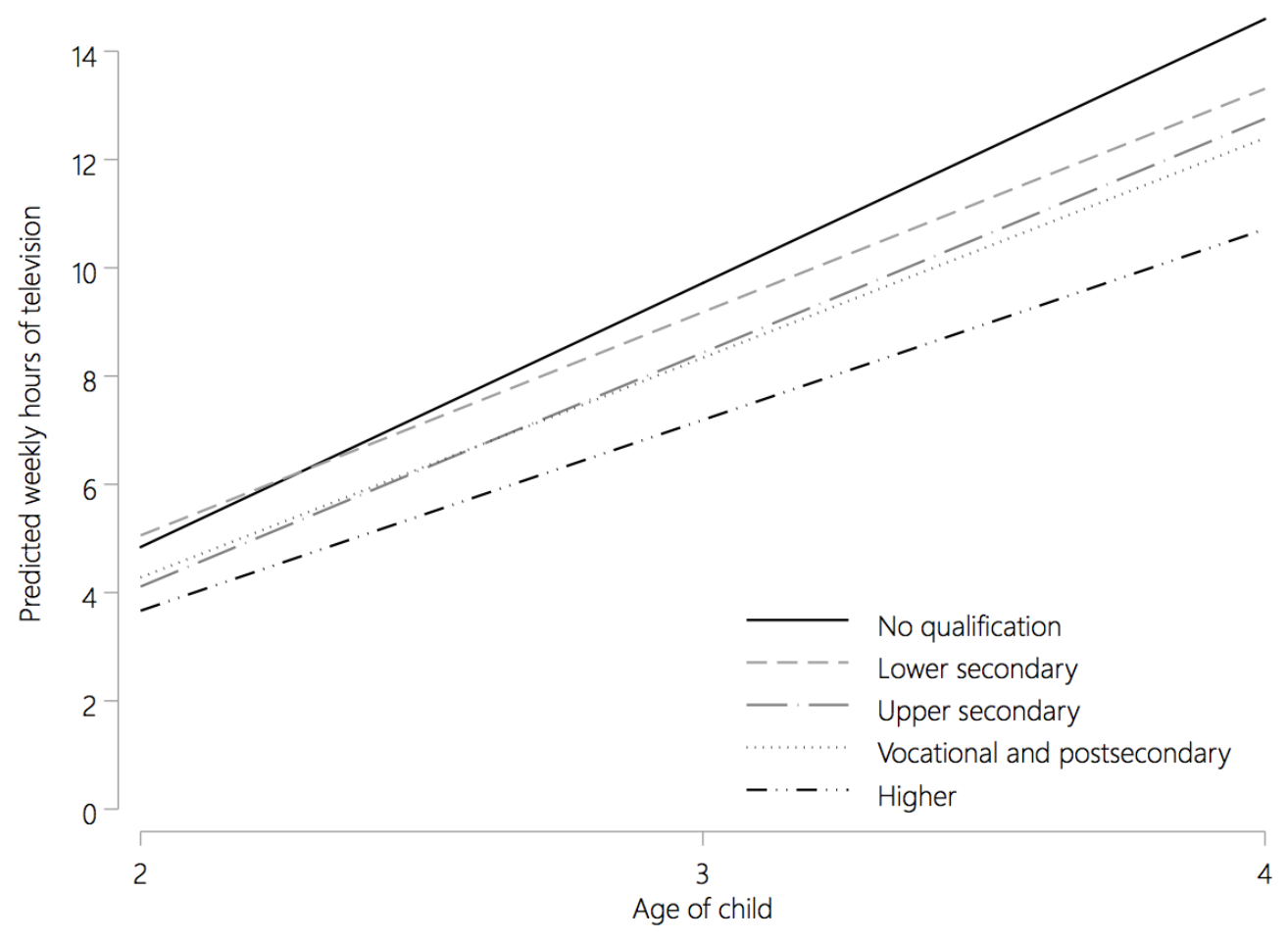


Figure 2. Associations between weekly hours of television around ages two to four and children's (standardized) outcomes around age 5 (with 90\% and 95\% confidence interval).

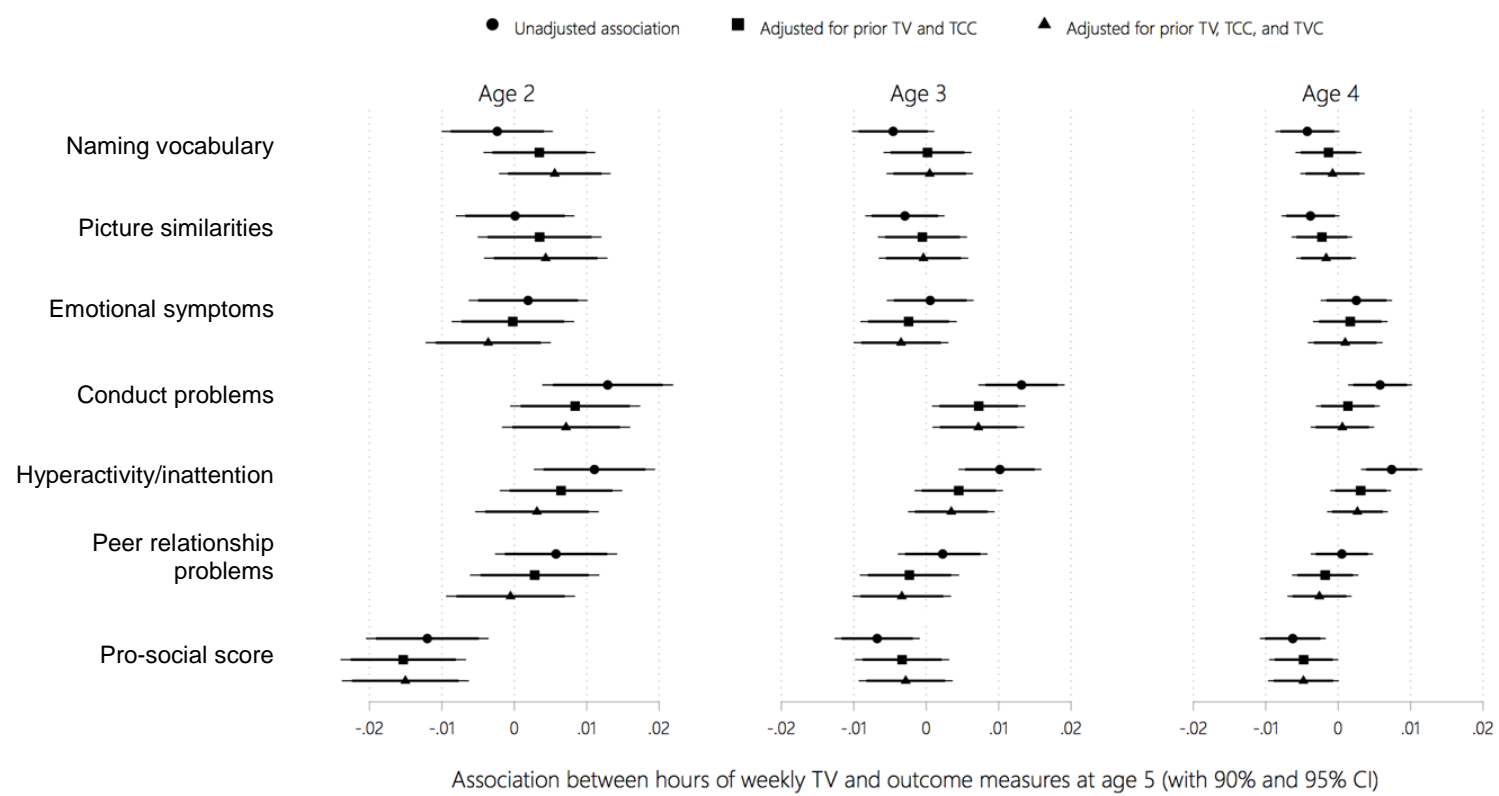

Note. $\mathrm{TCC}=$ time-constant covariates, $\mathrm{TVC}=$ time-varying covariates.

\subsection{Early television exposure and developmental outcomes}

In the next step, we probed the association of television exposure with different developmental outcomes. First, we considered the associations between television exposure at specific ages and children's developmental outcomes around age five. For each outcome and measurement of television exposure, Figure 2 shows the unadjusted association, the association after adjusting for prior television exposure and time-constant covariates (TCC), and the association after additionally adjusting for the time-varying covariates in that particular age (TVC). For the two ability measures and the pro-social score, higher values indicate better development, for all other measures they indicate worse development (see Table S5 in the appendix for the full results).

The unadjusted associations between weekly hours of television exposure at each age and the standardized Naming Vocabulary score - an indicator of expressive language ability - 
were negative but small (age 2: $\beta=-0.002$, $S E=0.004$; age $3: \beta=-0.003, S E=0.003$; age 4 : $\beta=-$ 0.003, $\mathrm{SE}=0.002$ ). For instance, around age 4, an increase of one hour of weekly television exposure is associated with a decrease in expressive language ability by 0.003 standard deviations. These negative associations vanished (age 4: $\beta=-0.000, \mathrm{SE}=0.002$ ) or transformed into small positive associations (age $2: \beta=0.006, \mathrm{SE}=0.004$; age $3: \beta=0.001, \mathrm{SE}=0.003$ ) after adjusting for prior television exposure, TCC and TVC. Hence, we can conclude that there is no relation between children's television exposure and expressive language ability.

For inductive reasoning ability as measured by the picture similarities score a similar pattern emerged. We found small negative marginal associations around ages 3 and 4 (age 3: $\beta=-0.002, \mathrm{SE}=0.003$; age $4: \beta=-0.003, \mathrm{SE}=0.002)$ and a small positive association around age $2(\beta=0.001, \mathrm{SE}=0.004)$. Adjusting for the different sets of covariates reduced the negative associations around ages 3 and 4 even further and slightly increased the positive association around age 2. Again, we can conclude that the amount of television children watch during the week has no association with their inductive reasoning ability.

The associations between children's weekly television exposure at each considered age and later emotional problems were positive but also small in the unadjusted case (age 2: $\beta=0.002, \mathrm{SE}=0.004$; age 3: $\beta=0.000, \mathrm{SE}=0.003$; age $4: \beta=0.002, \mathrm{SE}=0.002)$. After adjusting for prior television exposure and all measured time-constant and time-varying confounders, the associations reduced (age 4: $\beta=0.000, \mathrm{SE}=0.002$ ) or became slightly negative (age $2: \beta=-0.004$, $\mathrm{SE}=0.004$; age 3: $\beta=-0.004, \mathrm{SE}=0.003$ ). We also found small unadjusted positive associations between weekly hours of television exposure at early ages and peer relationship problems around age 5 (age 2: $\beta=0.006, \mathrm{SE}=0.004 ;$ age $3: \beta=0.002, \mathrm{SE}=0.003$; age 4: $\beta=0.001$, $\mathrm{SE}=0.002$ ). Likewise, they turned into slightly negative associations after accounting for prior television exposure and TCC and TVC (age 2: $\beta=-0.001, \mathrm{SE}=0.004$; age 3: $\beta=-0.004$, $\mathrm{SE}=0.003$; age 4: $\beta=-0.002, \mathrm{SE}=0.002$ ). Also, for emotional problems and peer relationship 
problems, there appears to be no meaningful association with the extent of children's television exposure.

Figure 2 revealed positive associations between the amount of early television exposure and hyperactivity/inattention around age 5 when unadjusted (age 2: $\beta=0.011, \mathrm{SE}=0.004$; age 3: $\beta=0.010, \mathrm{SE}=0.003$; age 4: $\beta=0.007, \mathrm{SE}=0.002$ ). However, these reduced markedly after adjusting for the available covariates, particularly at ages two and three (age 2: $\beta=0.003$, $\mathrm{SE}=0.004$; age $3: \beta=0.003, \mathrm{SE}=0.003$; age $4: \beta=0.003, \mathrm{SE}=0.002$ ).

Figure 3. Associations between average weekly hours of television through ages two to four and children's (standardized) outcomes around age five (with 90\% and 95\% confidence interval).

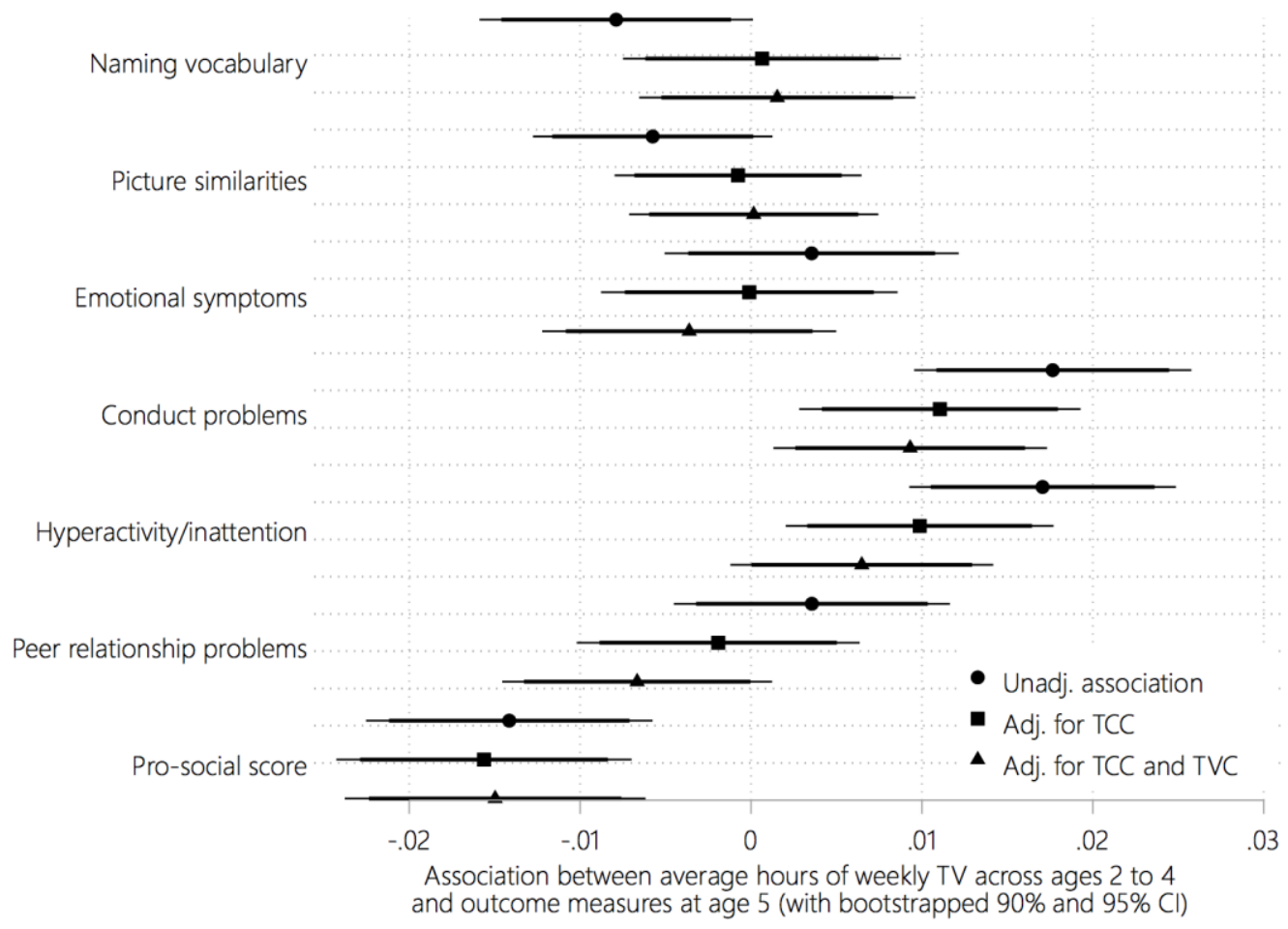

Note TCC $=$ time-constant covariates, $\mathrm{TVC}=$ time-varying covariates. 
Positive and more substantive unadjusted associations also emerged for conduct problems (age 2: $\beta=0.013, \mathrm{SE}=0.005$; age $3: \beta=0.012, \mathrm{SE}=0.003$; age $4: \beta=0.004, \mathrm{SE}=0.002$ ). After adjusting for prior television exposure and TCC, associations at all ages reduced (age 2: $\beta=0.010, \mathrm{SE}=0.004$; age 3: $\beta=0.006, \mathrm{SE}=0.003$; age 4: $\beta=0.001, \mathrm{SE}=0.002$ ). Further adjusting for TVC appeared to have only little impact on the associations between television exposure and conduct problems. While the adjusted association was virtually zero around age 4 (with $\mathrm{SE}=0.002)$, it remained stronger around age $2(\beta=0.009, \mathrm{SE}=0.004)$ and around age $3(\beta=0.006$, $\mathrm{SE}=0.003)$.

Finally, Figure 2 provides estimates for marginal and adjusted associations between children's television exposure and pro-social behavior around age 5. We found a negative relation for each age looking at unadjusted associations (age 2: $\beta=-0.012, \mathrm{SE}=0.004$; age 3 : $\beta=-$ 0.006, $\mathrm{SE}=0.003$; age $4: \beta=-0.005, \mathrm{SE}=0.002)$. Again, covariate adjustment reduced these associations with the exception of age 2 (age 2: $\beta=-0.013, \mathrm{SE}=0.004$; age 3 : $\beta=-0.002$, $\mathrm{SE}=0.003$; age 4: $\beta=-0.004, \mathrm{SE}=0.002)$.

To sum up, we find robust associations only between television exposure and conduct problems around age 3 and age 4 and between television exposure and pro-social behavior around age 2 after accounting for our time-constant and time-varying confounders. However, effect sizes are substantively small and do not exceed two per cent of the standard deviation in the respective outcome.

In the next step, we estimated associations between average television exposure across ages two to four and children's developmental outcomes around age five. Figure 3 summarizes the respective results and reproduces the patterns found in the previous analyses. There were only small associations between cumulative television exposure and children's expressive language ability, inductive reasoning ability, and emotional symptoms, both before and after covariate adjustment. While positive for the marginal association, the association between 
average weekly hours of television and peer relationship problems turned slightly negative after adjusting for the measured covariates. Again, we found more substantive associations for conduct problems, hyperactivity/inattention, and the pro-social score. The positive association between cumulative exposure to television and children's conduct problems around age 5 remained after covariate adjustment. For hyperactivity/inattention, we found a positive association with cumulative television exposure that decreased after adjusting for covariates. Lastly, we found a negative association between cumulative television exposure and pro-social behavior which remained almost the same after accounting for time-constant and time-varying covariates. As with the results for the separate ages, however, these associations are small and do not exceed two percent of the standard deviations in the respective outcomes.

Figure 4. Associations between average weekly hours of television through ages two to four and children's (standardized) outcomes around age five (with 90\% and 95\% confidence interval) by parental education.

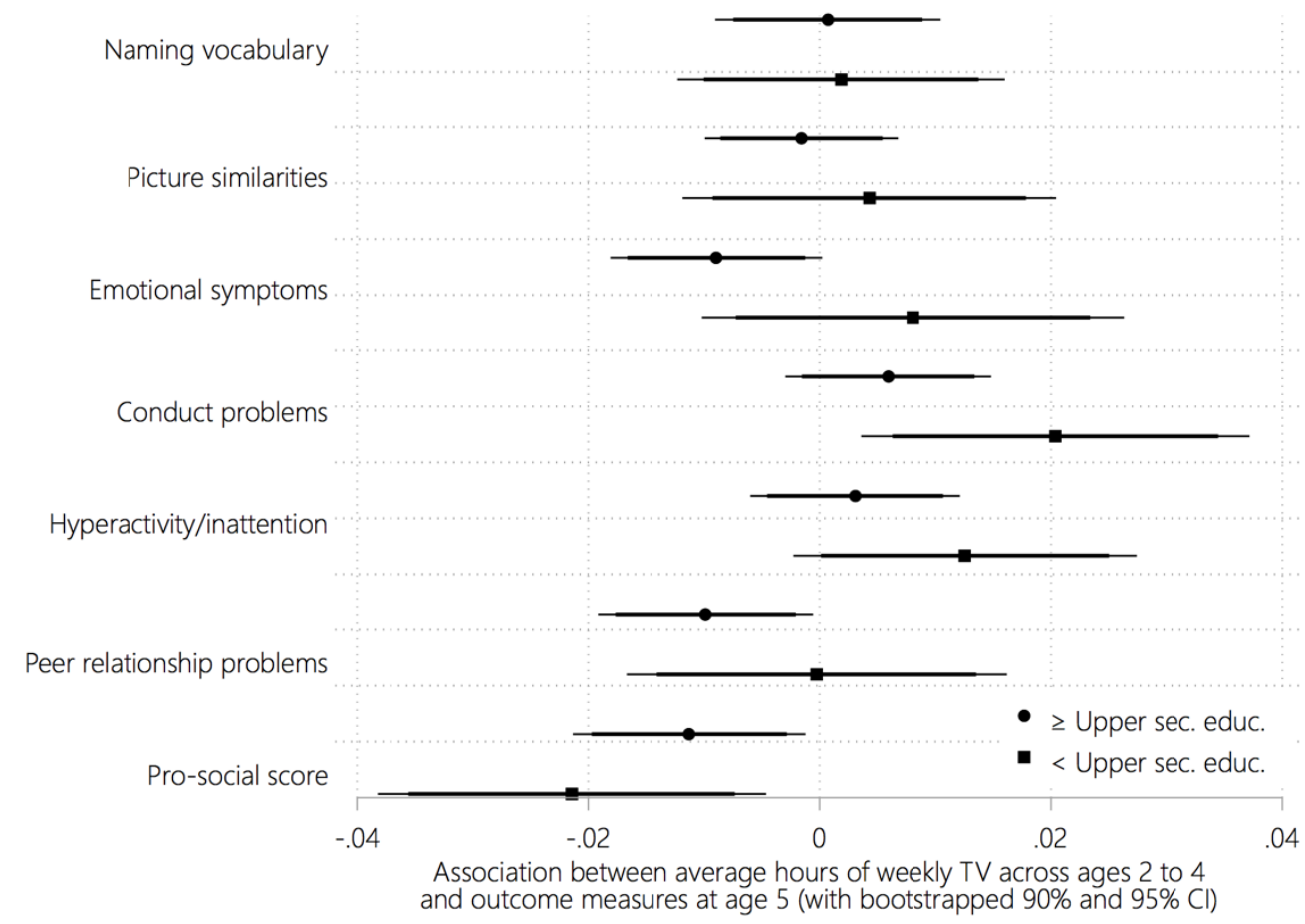




\subsection{Heterogeneity by parental education}

In our final analysis, we investigated variation in the association between average weekly television exposure and children's developmental outcomes by parental education. To this aim, we ran the RWR models that adjust for all TCC and TVC separately for children whose parents had at least upper secondary education and those whose parents had an education below. The results shown in Figure 4 provide some evidence for our hypothesis that television exposure may be more detrimental for children from lower social strata. The positive association for conduct problems and the negative association for pro-social behavior were indeed stronger for children whose parents had less than upper secondary education. Furthermore, the association between weekly hours of television exposure and emotional symptoms was negative for children of parents with higher upper secondary education, whereas for the other group it was positive. The results for hyperactivity/inattention also point to a stronger negative impact of television exposure for children of parents who did not obtain an upper secondary education. For the other developmental outcomes, there are hardly any differences between both groups. Effect sizes, however, need to be interpreted with caution, in particular for children whose parents obtained an education below upper secondary, given the large confidence intervals.

\subsection{Supplementary analyses}

Additional measures of expressive language ability and inductive reasoning ability around age 3 provide some leverage to assess the extent of confounding and reverse causation as suggested in the literature (e.g., Radesky et al. 2014). To this end, we analyzed the association between TV exposure around age 4 and changes in these ability scores between age 3 and age 5. Using such a change score eliminates the influence of any time-constant determinants of expressive language and inductive reasoning ability. Furthermore, we could also test whether inclusion of the lagged test score resulted in any substantive changes in 
coefficient for TV exposure around age 4. The results shown in Table 1 also reveal only small associations that are not substantively different from the analyses reported above. Therefore, this analysis did not provide any evidence that unmeasured confounding is a major issue in our analyses.

Table 1. Summary of WLS models predicting change in standardized developmental outcomes between ages three and five from hours of weekly TV consumption around age 4 and covariates around age $3(N=2,587$ children)

\begin{tabular}{|c|c|c|c|c|}
\hline & M1 & M2 & M3 & M4 \\
\hline \multicolumn{5}{|l|}{ Naming vocabulary } \\
\hline \multirow[t]{2}{*}{ Hours of TV/week (age 4) } & -0.004 & -0.004 & -0.002 & -0.002 \\
\hline & $(0.002)$ & $(0.002)$ & $(0.002)$ & $(0.002)$ \\
\hline \multirow[t]{2}{*}{ Naming vocabulary (age 3) } & & & & $-0.541^{* * *}$ \\
\hline & & & & $(0.023)$ \\
\hline$R^{2}$ & 0.001 & 0.021 & 0.026 & 0.283 \\
\hline \multicolumn{5}{|l|}{ Picture similarities } \\
\hline \multirow[t]{2}{*}{ Hours of TV/week (age 4) } & -0.005 & $-0.006^{*}$ & $-0.006^{*}$ & -0.002 \\
\hline & $(0.003)$ & $(0.003)$ & $(0.003)$ & $(0.002)$ \\
\hline \multirow[t]{2}{*}{ Picture similarities (age 3 ) } & & & & $-0.750 * * *$ \\
\hline & & & & $(0.022)$ \\
\hline \multicolumn{5}{|l|}{ Model includes: } \\
\hline TCC & & $\mathrm{X}$ & $\mathrm{X}$ & $\mathrm{X}$ \\
\hline TVC (age 3) & & & $\mathrm{X}$ & $X$ \\
\hline$R^{2}$ & 0.001 & 0.011 & 0.022 & 0.373 \\
\hline
\end{tabular}

Note. ${ }^{*} p<0.05,{ }^{* *} p<0.01,{ }^{* * *} p<0.001$; Robust standard errors in parentheses; $\mathrm{TCC}=$ time-constant covariates; TVC $=$ time-varying covariates 


\section{Discussion and Conclusions}

This paper investigated television exposure during early childhood by parental education and its consequences for the development of language, inductive reasoning, and different behavioral problems around age 5. Thereby, we contributed to the debate on the role of children's leisure activities for differences in life course outcomes. We improved upon most previous studies by using a large and representative sample of Scottish children and by accounting for a richer set of time-constant and time-varying covariates. Most importantly, we also considered the cumulative effect of television exposure through early childhood and investigated differences in the association between television exposure and children's outcomes by parental education.

We found evidence for differences by parental education in both level and growth of television exposure across the ages of two to four. An initial gap between children whose parents had no qualification and children whose parents had a degree of around 1.3 hours grew to roughly 4 hours around age four. Hence, parents with different educational background vary in the amount that they let their children watch television and this gap appears to widen when children become older. This is line with previous research on social disparities in parental time spent with children on television exposure and cultural activities more widely (Lareau 2003; Altintas 2012; Bihagen and Katz-Gerro 2000; Gracia 2015). Although this result seems to be robust, the question remained whether these social disparities in leisure activities such as television exposure have consequences for social inequalities in life course outcomes.

For the children in our sample, television exposure, both around different ages and as average over all ages, was only weakly associated with different developmental outcomes with more pronounced associations for conduct problems and pro-social behavior. However, even those associations were small compared to those for other covariates such as children's sex or mothers' views on the importance of educational activities (see Table S5 in the appendix). For 
example, the difference in pro-social score between boys and girls was roughly equivalent to the difference associated with 21 hours of television per week around age 2 . The pro-social score of children with mothers who regarded educational activities as important was 0.23 standard deviations higher than that of other children, a difference associated with roughly 16 hours of television per week around age 2. Although our final analyses revealed stronger associations between cumulative television exposure and behavioral problems for children whose parents had lower education, these associations remained small (less than 0.02 standard deviations) compared to the effect sizes of aforementioned confounders.

Overall, our results thus provided no evidence for a substantive adverse effect of television exposure in the family setting on children's vocabulary, inductive reasoning ability, and behavioral development. Our results challenge previous observational studies which claim early television exposure has a substantial impact on cognitive and language development (Byeon and Hong 2015; Chonchaiya and Pruksananonda 2008; Huang and Lee 2010; Tomopoulos et al. 2010; Zimmerman and Christakis 2005; Zimmerman et al. 2007). This contradiction in results is likely due to our rich set of confounders that were not included in previous studies (Foster and Watkins 2010). However, our results are in line with other studies that found a weak link between television exposure and behavioral problems using large-scale survey data (Foster and Watkins 2010; Parkes et al. 2013; Stevens and Muslow 2006).

Of course, these causal interpretations of our estimates rest on the strong and unverifiable assumption that there are no (strong) unmeasured confounders. To gain some insights about the potential role of unmeasured confounding we exploited the fact that GUS had already measured language ability and inductive reasoning around age three. We were, therefore, able to estimate the association between television exposure around age four and changes in these test scores. Additionally, we also estimated the association conditional on the test scores around age three. Likewise, these additional analyses did not reveal a substantial 
association between television exposure and these ability measures. This sensitivity analysis and the number of theoretically relevant (time-varying) covariates included in our analyses provide some confidence that the amount of confounding bias is limited.

Nonetheless, we need to consider several additional caveats when interpreting the results. First, our study is restricted to the amount of television exposure during a typical week, and we do not consider the content and context of children's television exposure. There is ample evidence to suggest that what children watch, and how they watch it, shapes the impact television exposure has on children's development (Kostyrka-Allchorne, Cooper and Simpson 2017). Children raised in a different socio-economic environment may not only differ regarding the quantity of television exposure but also the quality of content and parental presence and interactions. These differences may explain why television exposure has a stronger impact on conduct problems and prosocial behavior for children whose mothers have lower qualifications.

Second, we used a global measure of TV consumption: the total number of hours children watch television during an average week. Viewing diaries are deemed to be more accurate than recalled estimates of TV consumption (e.g. Rich, Bickham and Shrier 2015). In the GUS study, mothers reported their children's television exposure, and some mothers may overestimate, while others underestimate, how much television their children watch during a typical week. Hence, we cannot exclude the possibility of attenuation bias in our study. However, if so, it seems likely that mothers generally underestimate their children's television exposure. Comparing different ways of measuring television exposure, Borzekowski and Robinson (1999) did not find any indication of a social desirability bias regarding self-reported television exposure. There is also no reason to assume that this bias is more pronounced among mothers with lower education or that the accuracy of self-reported television exposure varies 
between mothers with different qualifications, i.e. random measurement error differs between the considered groups.

Third, we did not consider television exposure among infants below two years of age nor children over four years of age. Associations between weekly hours of television exposure and developmental outcomes may differ when considering television watching in the earliest stage of the life course or for children starting primary school and beyond (Hofferth 2010).

Fourth, our study is restricted to the analysis of consequences of TV exposure on children's development. We did not consider the amount of screen time on other digital devices and how it affects children's language growth, cognitive ability and behavioral development. Television continues, however, to be more popular than newer forms of media among younger children (Kostyrka-Allchorne, Cooper and Simpson 2017).

Under the premise to accept the causal assumptions, we found only limited evidence for any harmful (or beneficial) effects of children's television exposure on their developmental outcomes. Our theoretical considerations discussed two potential mechanisms for why television exposure may be detrimental to children's development: a direct effect via characteristics of television and an indirect effect via less frequent engagement in more stimulating interactions and activities.

The small differential impact of television exposure on conduct problems/prosocial behavior by parental education hints - if at all - at the indirect mechanism. Less educated parents may not have the resources, time or family support to compensate for their children's hours spent on television exposure by engaging them in other meaningful ways. Lower quality and quantity of parent-child interactions and activities may lead to conduct problems and antisocial behavior. Alternatively, children's experience of television exposure may differ between mothers of varying education. It may well be the case that highly educated parents watch television together with their children, more carefully choose the type of program and engage 
with their children throughout the program while due to constraints lower educated mothers leave their children unattended in front of the television.

What do these results imply for the cultural consumption literature? We found a social gradient in the amount of television exposure in children's early ages, but the harmful consequences of television on children's development are less pronounced than often assumed. This is in line with research showing that family experiences appear to account for only a small proportion of the achievement gap between children from different class backgrounds (e.g. Bodovski and Farkas 2008; Cheadle 2008). Nevertheless, we cannot exclude the possibility that children's television exposure has an impact on educational attainment and may to some extent explain social inequalities in education. However, this mechanism via television exposure - if it exists - seems to be not transmitted through differences in early cognitive and language development but via children's behavior that may impede learning (DiPrete and Jennings 2012) or may not conform to school norms and expectations (Duncan and Magnuson 2011). Our results highlight the necessity to study the causal relationships between cultural consumption and children's development or educational attainment before drawing conclusions on their role in social stratification processes.

Although our study longitudinally measures television exposure and thus makes an essential contribution to the literature, future research should be concerned with the long-term impact of television exposure patterns throughout early childhood and adolescence on educational attainment and other life course outcomes such as health. It may also be worthwhile to differentiate the cumulative impact of television watching on children's developmental outcomes by content and context of children's television exposure. 


\section{References}

Altintas, E. 2012. Parents' Time with Children: Micro and Macro Perspectives. University of Oxford.

Anand, Sowmya and J. O. N. A. Krosnick. 2005. "Demographic Predictors of Media Use Among Infants , Toddlers , and Preschoolers." American Behavioral Scientist 48(5):539-61.

Anderson, D. R. and T. A. Pempek. 2005. "Television and Very Young Children." American Behavioral Scientist 48(5):505-22.

Anderson, S., Bradshaw, P., Cunningham-Burley, S., Hayes, F., Jamieson, L., MacGregor, A., et al. 2007. Growing Up In Scotland: A study following the lives of Scotland's children. Edinburgh, UK: Scottish Executive.

Armstrong, G. B. and Greenberg, B. S. 1990. "Background Television as an Inhibitor of Cognitive Processing." Human Communication Research 16(3):355-86.

Aschaffenburg, K. and Maas, I. 1997. "Cultural and Educational Careers: The Dynamics of Social Reproduction." American Sociological Review 62(4):573-87.

Barr, R. and Hayne, H. 1999. "Developmental Changes in Imitation from Television during Infancy." Child Development 70(5):1067-81.

Barr, R., Lauricella, A., Zack, E. and Calvert, S. 2010. "Infant and Early Childhood Exposure to Adult-Directed and Child-Directed Television Programming: Relations with Cognitive Skills at Age Four." Merrill-Palmer Quarterly 56(1):21-48.

Barr, R., Muentener, P. and Garcia, A. 2007. "Age-Related Changes in Deferred Imitation from Television by 6- to 18-Month-Olds." Developmental Science 10(6):910-21.

Bernardi, F. 2014. "Compensatory Advantage as a Mechanism of Educational Inequality." Sociology of Education 87(2):74-88.

Bihagen, E. and Katz-Gerro, T. 2000. "Culture Consumption in Sweden: The Stability of Gender Differences." Poetics 27(5-6):327-49.

Blankson, O’Brien, Leerkes, Calkins, and Marcovitch. 2015. "Do Hours Spent Viewing Television at Ages 3 and 4 Predict Vocabulary and Executive Functioning at Age 5?" Merrill-Palmer Quarterly 61(2): 264-289.

Bodovski, K., \& Farkas, G. 2008. "Concerted cultivation” and unequal achievement in elementary school. Social Science Research, 37(3), 903-919.

Borzekowski, D. L. G. and Robinson, T. N. 1999. "Viewing the Viewers: Ten Video Cases of Children's Television Viewing Behaviors." Journal of Broadcasting and Electronic Media 43(4):506-28.

Bourdieu, P., \& Passeron, J.-C. 1990. Reproduction in Education, Society and Culture. London: Sage Publications.

Byeon, H. and Hong, S. 2015. "Relationship between Television Viewing and Language Delay in Toddlers: Evidence from a Korea National Cross-Sectional Survey." PLoS ONE 10(3):1-12.

Certain, L. K. and R. S. Kahn. 2002. "Prevalence, Correlates, and Trajectory of Television Viewing Among Infants and Toddlers." Pediatrics 109(4): 634-642.

Chanfreau, J., M. Barnes, W. Tomaszewski, D. Philo, J. Hall, \& S. Tipping (2011) Growing Up in Scotland: Change in early childhood and the impact of significant events, Edinburgh: Scottish Government

Cheadle, J. E. 2008. Educational Investment, Family Context, and Children's Math and Reading Growth from Kindergarten Through the Third Grade. Sociology of Education, 81(1), 1-31.

Cheadle, Jacob E. 2009. "Parent Educational Investment and Children's General Knowledge Development.” Social Science Research 38(2):477-91. 
Cheng, S. et al. 2010. "Early Television Exposure and Children's Behavioral and Social Outcomes at Age 30 Months." Journal of Epidemiology 20(Supplement II):482-89.

Chonchaiya, W. and Pruksananonda, C. 2008. "Television Viewing Associates with Delayed Language Development." Acta Paediatrica 97(7):977-82.

Christakis, D. A. et al. 2009. "Audible Television and Decreased Adult Words, Infant Vocalizations, and Conversational Turns." Archives of Pediatrics \& Adolescent Medicine 163(6):554.

Christakis, D. A. 2009. "The Effects of Infant Media Usage: What Do We Know and What Should We Learn?" Acta Paediatrica 98(1):8-16.

Christakis, Dimitri A., Beth E. Ebel, Frederick P. Rivara, and Frederick J. Zimmerman. 2004. "Television, Video, and Computer Game Usage in Children under 11 Years of Age." Journal of Pediatrics 145(5):652-56.

Christakis, D. A., Zimmerman, F. J., DiGiuseppe D. L., and McCarty, C. A.. 2004. "Early Television Exposure and Subsequent Attentional Problems in Children." Pediatrics 113(4):708-13.

Christakis, D. A., Zimmerman, F. J., and Garrison, M. M. 2007. "Effect of Block Play on Language Acquisition and Attention in Toddlers." Archives of Pediatrics \& Adolescent Medicine 161(10):967.

Christakis, D. A., Ramirez, J. S. B., Ferguson, S. M., Ravinder, S., \& Ramirez, J. M. 2018. How early media exposure may affect cognitive function: A review of results from observations in humans and experiments in mice. Proceedings of the National Academy of Sciences, 115(40): 9851-9858.

Christopher, Micaela E. et al. 2012. "Predicting Word Reading and Comprehension with Executive Function and Speed Measures across Development: A Latent Variable Analysis." Journal of Experimental Psychology: General 141(3): 470.

Cillero, I. H., and Jago, R. 2010. Systematic Review of Correlates of Screen-viewing Among Young Children. Preventive medicine 51(1): 3-10.

Condon, J. T. and Corkindale, C. J. 1998. "The Assessment of Parent-to-Infant Attachment: Development of a Self-Report Questionnaire Instrument." Journal of Reproductive and Infant Psychology 16(1):57-76.

Conners-Burrow, Nicola A., Lorraine M. Mckelvey, and Jill J. Fussell. 2011. "Social Outcomes Associated with Media Viewing Habits of Low-Income Preschool Children." Early Education and Development 22(2):256-73.

Cooper, N. R., C. Uller, J. Pettifer, and F. C. Stolc. 2009. "Conditioning Attentional Skills: Examining the Effects of the Pace of Television Editing on Children's Attention." Acta Paediatrica 98(10):1651-55.

Courage, M. L., Murphy, A. N., Goulding S., and Setliff, A. E. 2010. "When the Television Is on: The Impact of Infant-Directed Video on 6- and 18-Month-Olds' Attention during Toy Play and on Parent-Infant Interaction." Infant Behavior and Development 33(2):176-88.

Cragg, Lucy and Camilla Gilmore. 2014. "Skills Underlying Mathematics: The Role of Executive Function in the Development of Mathematics Proficiency." Trends in Neuroscience and Education 3(2): 63-68.

DiMaggio, P. 1982. "Cultural Capital and School Success: The Impact of Status Culture Participation on the Grades of U.S. High School Students ." American Sociological Review 47(2):189-201.

DiPrete, T. A. and J. L. Jennings. 2012. "Social and Behavioral Skills and the Gender Gap in Early Educational Achievement." Social Science Research 41:1-15.

Donnellan, M. B. and Ferguson, C. J. 2014. "Supersizing Effect Sizes Raises Concerns: A Reply to Zimmerman (2014).” Developmental Psychology 50(1):141-42. 
Duch, Helena et al. 2013. "Association of Screen Time Use and Language Development in Hispanic Toddlers: A Cross-Sectional and Longitudinal Study." Clinical Pediatrics 52(9):857-65.

Dumais, S. A. 2002. "Cultural Capital, Gender, and School Success: The Role of Habitus." Sociology of Education 75(1):44.

Duncan, G. J. and Magnuson, K. 2011. "The Nature and Impact of Early Achievement Skills, Attention Skills, and Behavior Problems.” In G. J. Duncan, \& R. J. Murnane (Eds.), Whither Opportunity: Rising inequality, schools, and children's life chances (pp. 47-69). New York, NY: Russell Sage.

Elwert, F. and C. Winship. 2014. "Endogenous Selection Bias: The Problem of Conditioning on a Collider Variable." Annual Review of Sociology 40(1):31-53.

Espinosa, Linda M., James M. Laffey, Tiffany Whittaker, and Yanyan Sheng. 2006.

"Technology in the Home and the Achievement of Young Children: Findings from the Early Childhood Longitudinal Study." Early Education and Development 17(3): 421441.

Fender, J. G., Richert, R. A., Robb, M. B., and Wartella, E. 2010. "Parent Teaching Focus and Toddlers' Learning from an Infant DVD." Infant and Child Development 19(6):613-27.

Ferguson, C. J. and M. B. Donnellan. 2014. "Is the Association between Children's Baby Video Viewing and Poor Language Development Robust? A Reanalysis of Zimmerman, Christakis, and Meltzoff (2007)." Developmental Psychology 50(1):129-37

Fidler, A. E., Zack, E. and Barr, R. 2010. "Television Viewing Patterns in 6- to 18-MonthOlds: The Role of Caregiver-Infant Interactional Quality." Infancy 15(2):176-96.

Foster, E.M. and Watkins, S. 2010. "The Value of Reanalysis: TV Viewing and Attention Problems." Child Development 81(1):368-75.

Geist, EA and M. Gibson. 2000. "The Effect of Network and Public Television Programs on Four and Five Year Olds Ability to Attend to Educational Tasks." Journal of Instructional Psychology 27(4): 250.

Gentzkow, M. and Shapiro, J. M. 2008. "Preschool Television Viewing and Adolescent Test Scores: Historical Evidence from the Coleman Study." The Quarterly Journal of Economics 123(1):279-323.

Greeman, Emily, Katerina Bodovski, and Katherine Reed. 2011. "Neighborhood Characteristics, Parental Practices and Children' s Math Achievement in Elementary School.

" Social Science Research 40(5):1434-44.

De Graaf, N. D., P. M. De Graaf, and Kraaykamp, G. 2000. "Parental Cultural Capital and Educational Attainment in the Netherlands: A Refinement of the Cultural Capital Perspective." Sociology of Education 73(2):92.

Gracia, P. 2015. "Parent-Child Leisure Activities and Cultural Capital in the United Kingdom: The Gendered Effects of Education and Social Class." Social Science Research 52:290-302.

Grätz, M. 2014. "When Growing Up Without a Parent Does Not Hurt: Parental Separation and the Compensatory Effect of Social Origin." European Sociological Review 31(5):546-57.

Grieser, D. L. and Kuhl, P. K. 1988. "Maternal Speech to Infants in a Tonal Language: Support for Universal Prosodic Features in Motherese." Developmental Psychology 24(1):14-20.

Hayne, H., Herbert, J., and Simcock, G. 2003. "Imitation from Television by 24- and 30Month-Olds.” Developmental Science 6(3):254-61.

Hirsh-Pasek, K. et al. 1987. "Clauses Are Perceptual Units for Young Infants." Cognition 26(3):269-86. 
Hofferth, Sandra L. 2010. "Home Media and Children's Achievement and Behavior." Child Development 81(5):1598-1619.

Huang, F. and Lee, M. J. 2010. "Dynamic Treatment Effect Analysis of TV Effects on Child Cognitive Development." Journal of Applied Econometrics 25(3):392-419.

Hurtado, N., Marchman, V. A., and Fernald, A. 2008. "Does Input Influence Uptake? Links between Maternal Talk, Processing Speed and Vocabulary Size in Spanish-Learning Children." Developmental Science 11(6):31-39.

Huttenlocher, J. 1998. "Language Input and Language Growth." Preventive Medicine 27(27):195-99.

Jackson, D. B. 2018. Does TV viewing during toddlerhood predict social difficulties and conduct problems? Infant and Child Development, e2086.

Kirkorian, H. L., Pempek, T. A., Murphy, L. A., Schmidt, M. E., and Anderson, D. R.. 2009. "The Impact of Background Television on Parent - Child Interaction." Child Development 80(5):1350-59.

Koolstra, C. M. and van der Voort, T. H. A. 1996. "Longitudinal Effects of Television on Children's Leisure-Time Reading: A Test of Three Explanatory Models." Human Communication Research 23(1):4-35.

Koolstra, T. H. A. and C. M. van der Voort. 1997. "Television's Impact on Children's Reading Comprehension and Decoding Skills: A 3-Year Panel Study.” Reading Research Quarterly 32(2):128-52.

Kostyrka-Allchorne, Katarzyna, Nicholas R. Cooper, and Andrew Simpson. 2017. "The Relationship between Television Exposure and Children's Cognition and Behaviour: A Systematic Review." Developmental Review 44:19-58.

Kraaykamp, G. and Van Eijck, K. 2010. "The Intergenerational Reproduction of Cultural Capital: A Threefold Perspective.” Social Forces 89(1):209-31.

Krcmar, M., Grela, B., and Lin, K. 2007. "Can Toddlers Learn Vocabulary from Television? An Experimental Approach." Media Psychology 10(1):41-63.

Kuhl, P. K., F. M. Tsao, and Liu, H. M.. 2003. "Foreign-Language Experience in Infancy: Effects of Short-Term Exposure and Social Interaction on Phonetic Learning." Proceedings of the National Academy of Sciences 100(15):9096-9101.

Laidley, T., \& Conley, D. 201). The Effects of Active and Passive Leisure on Cognition in Children: Evidence from Exogenous Variation in Weather. Social Forces 91(1):129156.

Lareau, A. 2003. Unequal Childhoods: Class, Race, and Family Life. Berkeley: University of California Press.

Lillard, A. S. and J. Peterson. 2011. "The Immediate Impact of Different Types of Television on Young Children's Executive Function." Pediatrics 128(4):644-49.

Lillard, A. S., Drell M. B., Richey, E. M., Boguszewski, K., and Smith, E. D.. 2015. "Further Examination of the Immediate Impact of Television on Children's Executive Function." Developmental Psychology 51(6):792-805.

Lin, Ling Yi, Rong Ju Cherng, Yung Jung Chen, Yi Jen Chen, and Hei Mei Yang. 2015. "Effects of Television Exposure on Developmental Skills among Young Children." Infant Behavior and Development 38:20-26.

Linebarger, Deborah L., Rachel Barr, Matthew A. Lapierre, and Jessica T. Piotrowski. 2014. “Associations Between Parenting, Media Use, Cumulative Risk, and Children's Executive Functioning.” Journal of Developmental \& Behavioral Pediatrics 35(6):36777.

Mendelsohn, A. L. et al. 2008. "Infant Television and Video Exposure Associated With Limited Parent-Child Verbal Interactions in Low Socioeconomic Status Households." Archives of Pediatrics \& Adolescent Medicine 162(5):411-17. 
Mendelsohn, A. L. et al. 2010. "Do Verbal Interactions with Infants during Electronic Media Exposure Mitigate Adverse Impacts on Their Language Development as Toddlers?" Infant and Child Development 19(6):577-93.

Miller, C. J. et al. 2006. "Brief Report: Television Viewing and Risk for Attention Problems in Preschool Children." Journal of Pediatric Psychology 32(4):448-52.

Mistry, K. B., C. S. Minkovitz, D. M. Strobino, and D. L. G. Borzekowski. 2007. "Children's Television Exposure and Behavioral and Social Outcomes at 5.5 Years: Does Timing of Exposure Matter?" Pediatrics 120(4):762-69.

Nathanson, A. I., Aladé, F., Sharp, M. L., Rasmussen, E. E., and Christy, K. 2014. "The Relation between Television Exposure and Executive Function among Preschoolers." Developmental Psychology 50(5):1497-1506.

Kemler, N. D. G., Hirsh-Pasek, K., Jusczyk, P. W. and Cassidy, K. W.. 1989. "How the Prosodic Cues in Motherese Might Assist Language Learning." Journal of Child Language 16(1):55.

Notten, N. and Kraaykamp, G. 2009a. "Home Media and Science Performance: A CrossNational Study." Educational Research and Evaluation 15(4):367-84.

Notten, N. and Kraaykamp, G. 2009b. "Parents and the Media. A Study of Social Differentiation in Parental Media Socialization.” Poetics 37(3):185-200.

Notten, N. and Kraaykamp, G. 2010. "Parental Media Socialization and Educational Attainment: Resource or Disadvantage?" Research in Social Stratification and Mobility 28(4):453-64.

Okuma, K. and Tanimura, M. 2009. "A Preliminary Study on the Relationship between Characteristics of TV Content and Delayed Speech Development in Young Children." Infant Behavior and Development 32(3):312-21.

Pagani, Linda S., Caroline Fitzpatrick, Tracie A. Barnett, and Eric Dubow. 2010. "Prospective Associations between Early Childhood Television Exposure and Academic, Psychosocial, and Physical Well-Being by Middle Childhood." Archives of Pediatrics and Adolescent Medicine 164(5):425-31.

Parkes, A., Sweeting, H., Wight, D., and Henderson, M. 2013. "Do Television and Electronic Games Predict Children's Psychosocial Adjustment? Longitudinal Research Using the UK Millennium Cohort Study." Archives of Disease in Childhood 98(5):341-48.

Pempek, T. A., Kirkorian, H. L., and Anderson, D. R. 2014. "The Effects of Background Television on the Quantity and Quality of Child-Directed Speech by Parents." Journal of Children and Media 8(3):211-22.

Potter, Daniel, and Josipa Roksa. 2013. “Accumulating Advantages over Time: Family Experiences and Social Class Inequality in Academic Achievement." Social Science Research 42(4):1018-32.

Radesky, J. S., M. Silverstein, B. Zuckerman, and D. A. Christakis. 2014. "Infant SelfRegulation and Early Childhood Media Exposure.” Pediatrics 133(5):e1172-78.

Ribner, A., Fitzpatrick, C., \& Blair, C. 2017. Family socioeconomic status moderates associations between television viewing and school readiness skills. Journal of Developmental \& Behavioral Pediatrics, 38(3): 233-239.

Rich, Michael, David S. Bickham, and Lydia A. Shrier. 2015. "Measuring Youth Media Exposure: A Multimodal Method for Investigating the Influence of Media on Digital Natives." American Behavioral Scientist 59(14), 1736-1754.

Richert, R. A., Robb, M. B., Fender, J. G., and Wartella, E. 2010. "Word Learning From Baby Videos." Archives of Pediatrics \& Adolescent Medicine 164(5):432-37.

Rideout, V., Hamel, E., and Kaiser, F. F. 2006. "The Media Family: Electronic Media in the Lives of Infants, Toddlers, Preschoolers and Their Parents." The Henry J. Kaiser Family Foundation. Menlo Park, California. 
Robb, M. B., Richert, R. A., and Wartella, E. A. 2009. "Just a Talking Book? Word Learning from Watching Baby Videos." British Journal of Developmental Psychology 27(1):2745.

Robins, J. M., \& Hernán, M. A. 2009. Estimation of the causal effects of time-varying exposures. In G. Fitzmaurice, M. Davidian, G. Verbeke \& G. Molenberghs (Eds.), Longitudinal data analysis (pp. 553-597). Boca Raton, FL: CRC Press.

Robins, J. M., Hernan, M. A., \& Brumback, B. 2000. Marginal structural models and causal inference in epidemiology. Epidemiology, 11, 550-560.

Schmidt, M. E. et al. 2008. "The Effects of Background Television on the Toy Play Behavior of Very Young Children.” Child Development 79(4):1137-51.

Schmidt, M. E., Rich, M., Rifas-Shiman, S. L., Oken, E., and Taveras, E. M. 2009. "Television Viewing in Infancy and Child Cognition at 3 Years of Age in a US Cohort." Pediatrics 123(3):e370-5.

Schmitt, K. L. and D. R. Anderson. 2002. “Television and Reality: Toddelers' Use of Visual Information from Video to Guide Behaviour." Media Psychology 4(November):1-26.

ScotCen Social Research. 2013. Growing Up in Scotland: Cohort 1, Sweeps 1-6, 2005-2011 [computer file]. 11th Edition. Colchester, Essex: UK Data Archive [distributor]. SN: 5760. doi:10.5255/UKDA-SN-5760-4.

Setliff, A. E. and Courage, M. L. 2011. "Background Television and Infants' Allocation of Their Attention during Toy Play." Infancy 16(6):611-39.

Shonkoff, J. P., \& Phillips, D. A. (Eds.). 2000. From neurons to neighborhoods: The science of early child development. Washington, D.C.: National Academy Press.

Singer, J. L. and D. G. Singer. 1983. "Psychologists Look at Television: Cognitive, Developmental, Personality, and Social Policy Implications." American Psychologist 38(7):826-34

Stevens, T. and Muslow, M.. 2006. "There Is No Meaningful Relationship Between Television Exposure and Symptoms of Attention-Deficit/Hyperactivity Disorder." Pediatrics 117(3):665-72.

Suddendorf, T. 2003. "Early Representational Insight: Twenty-Four-Month-Olds Can Use a Photo to Find an Object in the World." Child Development 74(3):896-904.

Tanimura, M., Okuma, K., and Kyoshima, K. 2007. "Television Viewing, Reduced Parental Utterance, and Delayed Speech Development in Infants and Young Children." Archives of Pediatrics \& Adolescent Medicine 161(6):618-19.

Tomopoulos, S. et al. 2010. "Infant Media Exposure and Toddler Development." Archives of Pediatrics \& Adolescent Medicine 164(12):1105-11.

Torche, F. and Echevarría, G. 2011. "The Effect of Birthweight on Childhood Cognitive Development in a Middle-Income Country." International Journal of Epidemiology 40(4):1008-18.

Troseth, G. L. and DeLoach, J. S.. 1998. "The Medium Can Obscure the Message: Young Children's Understanding of Video.” Child Development 69(4):950-65.

Vandewater, E. A. et al. 2005. "When the Television Is Always On: Heavy Television Exposure and Young Children's Development." American Behavioral Scientist 48(5):562-77.

Weisleder, A. and Fernald, A. 2013. "Talking to Children Matters: Early Language Experience Strengthens Processing and Builds Vocabulary." Psychological Science 24(11):2143-52.

Winship, C. and Mare, R. D. 1992. "Models for Sample Selection Bias.” Annual Review of Sociology 18(1):327-50.

Wodtke, G. T. and Almirall, D. 2017. "Estimating Moderated Causal Effects with TimeVarying Treatments and Time-Varying Moderators: Structural Nested Mean Models and 
Regression with Residuals.” Sociological Methodology 8117501770118.

Wright, J. C. et al. 2001. "The Relations of Early Television Viewing to School Readiness and Vocabulary of Children from Low-Income Families: The Early Window Project." Child Development 72(5):1347-66.

Zimmerman, F. J. et al. 2009. "Teaching by Listening: The Importance of Adult-Child Conversations to Language Development." Pediatrics 124(1):342-49.

Zimmerman, F. J. 2014. "Where's the Beef? A Comment on Ferguson and Donnellan (2014)." Developmental Psychology 50(1):138-40.

Zimmerman, F. J. and Christakis, D. A. 2005. "Children's Television Viewing and Cognitive Outcomes." Archives of Pediatrics \& Adolescent Medicine 159(July):619-25.

Zimmerman, F. J., Christakis, D. A., and Meltzoff, A. N. 2007. "Television and DVD/video Viewing in Children Younger than 2 Years." Archives of Pediatrics \& Adolescent Medicine 161(5):473-79. 